\title{
Review
}

\section{A Review of Thrombosis and Antithrombotic Therapy in Microvascular Surgery}

\author{
D. Froemel ${ }^{a}, b \quad$ S.-J. Fitzsimons ${ }^{a} \quad$ J. Frank $^{c} \quad$ M. Sauerbier ${ }^{d} \quad$ A. Meurer ${ }^{b}$ \\ J.H. Barker ${ }^{a}$
}

${ }^{a}$ Frankfurt Initiative for Regenerative Medicine, and Departments of ${ }^{b}$ Orthopedic Surgery and

'Trauma, Hand and Reconstructive Surgery, Johann Wolfgang Goethe University, and ${ }^{\mathrm{d}}$ BG-Trauma

Center, Frankfurt, Germany

\section{Key Words}

Anticoagulation · Antithrombotic therapy · Microvascular surgery $\cdot$ Thrombosis

\begin{abstract}
Despite a remarkable expansion of microsurgery, there is still no international consensus about routinely used prophylactic antithrombotic agents. Most treatment regimens still use aspirin, heparin (low-molecular-weight and unfractionated heparin) or colloids (hydroxyphenylacetate $6 \% /$ dextran); however, clear evidence for the clinical benefit of an ideal administration regimen or one agent over the other has not yet been established. Instead of searching for the one regime that fits all, an increasing number of reviews from different disciplines describe multistep approaches that optimize what has been shown to be most promising. This includes the use of antithrombotic agents, proper risk assessment, secondary prevention and professional training to optimize microsurgical skills. In this review, we describe factors included in traditional approaches and also emphasize the value of good surgical technique, which while recognized by all to be one of the most important factors for success, receives less emphasis in reviews describing thrombosis prophylaxis in microvascular surgery.
\end{abstract}

Copyright $(2013$ S. Karger AG, Basel

\section{Introduction}

The number of microsurgical procedures performed each year has greatly expanded. This is due to the development of better and smaller instrumentation, widespread and standardized microsurgical training programs and a better understanding of the pathophysiology 
of manipulated tissues. The indications for free flap reconstruction have also been expanded in the last years due to a better and more refined understanding of flap anatomy and perfusion dynamics (perforator and free flaps).

When microsurgical technique is used to reconnect small blood vessels the threat of thrombotic occlusion is ever present, and is by far the leading cause of failure.

In our 1992 review 'Thrombosis and antithrombotic therapy in microvascular surgery' [1] we concluded that the best prophylaxis against thrombosis in microvascular surgery is 'excellent surgical technique and proper patient selection': this has not changed. In this review, 20 years hence, we provide the reader with a recapitulation of that which has not changed and an update on that which has, the latest antithrombotic approaches.

Because failure still occurs, even in the hands of the most technically skilled microsurgeon [2], antithrombotic medications continue to be used. The list of antithrombotic medications used is simple and has not changed in 20 years. The protocols used for administration of these drugs vary greatly, making it difficult to provide standard recommendations for the use of these agents in microvascular procedures.

When considering the use of antithrombotic medications in patients who will receive microvascular surgery it is important to take into consideration that some patients are already taking these drugs for general thrombosis prophylaxis. While heparin, specifically low-molecular-weight heparin (LMWH), is the antithrombotic drug of choice in surgical interventions, it is also administered chronically in patients with prothrombotic conditions and/ or with poor vessel status.

Rather than providing the reader with specific recommendations, herein we list various recommendations published in recent reviews and let the reader decide which works best in his/her hands. We review basic science and pathophysiological evidence that supports successful antithrombotic strategies in microvascular surgery, including risk assessment, technical considerations and pharmacological intervention. These topics will be presented in the same order as they present in surgical practice, i.e. pre-, intra- and postoperatively.

The role of platelets in hemostasis and thrombosis is beyond the scope of this review and will be discussed in detail in an accompanying article in this issue.

\section{Pathophysiology of Anastomotic Thrombosis}

Thrombosis results from a predominance of procoagulatory factors described by the 'Virchow Triad': blood flow stasis, vessel wall injury and hypercoagulability. Animal studies demonstrate a close association between arterial thrombosis/platelet aggregation and venous thrombosis/fibrin clotting [3]. Arterial thrombosis typically (90\%) manifests itself within the first $24 \mathrm{~h}$ postoperatively, whereas venous thrombosis occurs after $24 \mathrm{~h} \mathrm{[4]}$. While $80 \%$ of thrombotic occlusions occur in the first $48 \mathrm{~h}$ postoperatively [5], in most cases the pathophysiological cause can be traced back to the pre- and intraoperative phases.

\section{Preoperative Causes}

Preoperative causes of thrombosis are usually related to comorbidities like poor vessel status, posttraumatic vascular disease, smoking, diabetes, alcohol, immobilization, cancer, previous surgery, prior thrombosis and hereditary diseases [6]. Cofactors that can influence a patient's coagulatory status include impaired perfusion, e.g. in hemorrhagic shock or polytraumatized patients. Kwaan [7] concluded that 'a therapeutic approach limited to a single target of the underlying pathogenic factor, such as the use of anticoagulants, is insufficient and often unsuccessful. Simultaneous management of all the contributory factors should therefore be considered'. Most of the literature describing preoperative factors contributing 
Table 1. PubMed search

Froemel et al.: A Review of Thrombosis and Antithrombotic Therapy in Microvascular Surgery

\begin{tabular}{lr} 
PubMed Central search conducted on 18.05.2012 \\
\hline Search term used & $\begin{array}{l}\text { Articles cited } \\
\mathrm{n}\end{array}$ \\
\hline Thrombosis & 171,131 \\
Thrombosis and risk & 37,353 \\
Thrombosis and microvascular & 1,606 \\
Thrombosis and microvascular and microsurgery & 367 \\
Thrombosis and microvascular and microsurgery & \\
$\quad$ and risk & 63 \\
\hline
\end{tabular}

Table 2. Increased risk for thrombosis

\begin{tabular}{lll}
\hline Procedure & Increased risk for thrombosis & References \\
\hline Use of vein graft & Yes & Miller et al. [69] \\
Chronic wound at recipient site & Yes & Kroll et al. [5] \\
Suture material & No & Acland [8] \\
Suture incision & Yes & Acland [8] \\
\hline
\end{tabular}

to thrombosis derives from clinical studies of patients with heart attacks, stroke or deep vein thrombosis, and only a few pertain to patients receiving microvascular surgery. This is evident in table 1 that shows the results of a Medline search on the topic.

\section{Intraoperative Causes}

In human vessels, exposure of subendothelial structures to blood flow has been shown to have a greater impact on anastomotic thrombosis than endothelial dysfunction, i.e. vasospasm [8]. While clamping small blood vessels causes endothelial dysfunction with enhanced thrombocyte aggregation, firm clot formation only occurs when blood flow in the vessel comes in contact with proteins like collagens I and III in the subendothelium [9]. Table 2 shows examples of microvascular procedures that present higher risks of exposing subendothelial structures to blood flow and in doing so increase the intraoperative risk for thrombosis.

The role of vasospasm seems less important in thrombus formation as spasm alone does not increase clot formation [10]. However, narrowing of the vessel lumen, by reducing blood flow, and reducing the number of thrombocytes necessary to occlude the vessel can synergize with prothrombotic factors [1]. Vasospasm can be minimized by local application of papaverine hydrochloride. Fathi et al. [11] showed in rabbit ear vessels that botulinum toxin enhances vessel diameter and consequently venous and arterial anastomosis patency.

Factors that compress or irritate the vessel anastomosis, e.g. hematoma, tightly closed wounds, drainage tubes positioned too close to an anastomosis or tendon, and joint or muscle movements, can all pose threats to vessel patency and lead to failure of a replant or a new flap.

\section{Postoperative Causes}

Traditional postoperative risk factors include venous congestion due to major trauma of the extremity (endothelial damage in arteries and/or veins), decreased movement and wound 
Froemel et al.: A Review of Thrombosis and Antithrombotic Therapy in Microvascular Surgery

infection [12,13]. Kadota et al. [14] showed in their study of 24 patients that postoperative (day 5 or later) wound infection was the most common (54\%) cause of anastomotic thrombosis. They concluded by emphasizing the importance of early detection and appropriate management of wound infection for avoiding postoperative thrombosis of the vascular anastomosis.

Another, less studied, factor that may play a role in replant and free flap failure is occlusion of the microcirculation downstream from the arterial anastomosis. This was demonstrated in a free flap model of the rat femoral artery in which, following a simulated poor vessel anastomosis, both the upstream arterial anastomosis and the downstream flap microcirculation were directly viewed using intravital microscopy [15-18]. Using this model system, both thrombus formation upstream at the arterial anastomosis and capillary perfusion in the downstream microcirculation were simultaneously viewed and measured. The authors found that emboli breaking off from the upstream thrombus flushed downstream and caused a significant decrease in capillary perfusion in the microcirculation [16]. These findings were confirmed by treating animals with antithrombotic agents like heparin and reversing thrombus and embolus formation, and decreased capillary perfusion [17]. In addition to obstructing the microcirculation in replanted tissues and free flaps, the presence of small platelet-rich emboli could also cause local vasospasm via thromboxane $A_{2}$ [18]. Together these - emboli occlusion and vasospasm - could be responsible for replant and free flap failures in the absence of thrombosis at the microvascular anastomosis.

\section{Principles of Antithrombotic Therapy in Microvascular Surgery}

The best antithrombotic therapy is thorough preoperative risk assessment and surgical planning, meticulous intraoperative microvascular technique and careful postoperative monitoring to enable early detection and intervention.

\section{Preoperative Risk Assessment}

Thorough preoperative riskassessment requires careful assessment of a patient's history, including questions to detect hereditary diseases, coagulopathies and vasculopathies, i.e. a history of deep vein thrombosis and abortions. In the case of positive findings, several clinical, laboratory and genetic tests are available. Depending on the time and resources available, assessments can include imaging tests like thrombelastography (testing the efficiency of coagulation in blood) or Multiplate (bedside platelet analysis), which are becoming more routine. In order to minimize the risks of failure in high-risk patients, there is also the possibility of using vein interposition grafts or arteriovenous loops [12].

\section{Intraoperative Risk Assessment}

Meticulous intraoperative microsurgical technique requires excellent microsurgical training. Soon after the pioneers of microvascular surgery implemented the first successful procedures on small vessels in rabbit ears [19], the first clinical finger replants [20] and free flaps [21] were performed. Teaching this new skill became an integral part of training programs in plastic and reconstructive, trauma and orthopedic surgery. In the early days, training consisted of see one, do one and teach one, but since then has evolved into well-structured courses with step-by-step instruction on the skills necessary to perform these technically challenging surgeries. Today, teaching basic microsurgical skills takes place typically in 3- to 14-day courses that provide a mix of didactic lectures and hands-on training in live animals. There are many microsurgery teaching courses available, most of which are part of or closely affiliated with university-based postgraduate reconstructive surgery training 
Table 3. Recently published reviews

\begin{tabular}{lll}
\hline Review & Recommendations & \\
\cline { 2 - 3 } & important & to consider \\
\hline Askari et al. [66] & Excellent technique & $\begin{array}{l}\text { LMWH } \\
\text { Risk-adaptive protocols }\end{array}$ \\
\hline Schmitz et al. [67] & Excellent technique & $\begin{array}{l}\text { LMWH (UFH), start preoperatively } \\
\text { Bolus before reperfusion } \\
\text { Risk-adaptive protocols }\end{array}$ \\
\hline Brands et al. [68] & Excellent technique & $\begin{array}{l}\text { Routine deep venous thrombosis prophylaxis } \\
\text { Risk-adaptive protocols } \\
\text { Smoking cessation }\end{array}$ \\
& & $\begin{array}{l}\text { Acetylsalicylic acid, start preoperatively, heparin/ } \\
\text { dextran bolus (dextran administered for 5 days in } \\
\text { replants only) }\end{array}$ \\
\hline Conrad and Adams [43] & Excellent technique & \\
& &
\end{tabular}

programs, such as the Frankfurt Microsurgery Teaching Course [22]. Over the years, standardized teaching methods together with improved microsurgical instruments, sutures and microscopes have led to the introduction of technically challenging procedures and to higher success rates.

As made evident in table 3, good microsurgical technique is recognized as the single most important factor for success. Veravuthipakorn and Veravuthipakorn [2] highlighted the importance of solid surgical technique by showing that even without antithrombotic intervention, near $100 \%$ success rates could be achieved in free flap and replant procedures when solid microsurgical technique was observed.

\section{Postoperative Risk Assessment}

Careful postoperative monitoring is essential as it allows early detection and intervention, and thus the possibility of salvaging a failing implant or free flap. In a retrospective review of 290 free flaps used for breast reconstruction, Vijan and Tran [23] showed a significant difference in salvage rates between flaps that were reexplored earlier versus later. They observed that flaps taken back to the operating room for reexploration within 128 min postoperatively were salvaged, while those taken back after 228 min failed. This emphasizes the importance of postoperative monitoring to enable early detection and intervention.

Most decisions to take patients back to the operating room for reexploration are based on clinical findings. In cases where these monitoring devices are not available, it is recommended to keep patients in intermediate care for observation for $48 \mathrm{~h}$, the period when most complications occur. Also, it is essential to keep the hemoglobin levels above $7.5 \mathrm{~g} / \mathrm{dl}$ and maintain body and room temperatures above 36 and $22^{\circ} \mathrm{C}$, respectively. Care must be taken to keep partial thromboplastin time between 42 and 45 seconds. Finally, patients should be given antibiotics routinely in order to avoid postoperative infection and they should not consume nicotine, coffee or chocolate 6 weeks postoperatively.

Where monitoring devices are used, ultrasound Doppler is the most common (16.2\%), followed by LICOX $\mathrm{p}_{2}$ monitor (5.9\%) and finally thermosensors (4.4\%). The most commonly used $(43.1 \%)$ monitoring protocol described in the literature was hourly until day 3 , followed by every $2 \mathrm{~h}$ until day 5 and finally at decreasing intervals until discharge from the hospital. In recent years, new approaches have been introduced. These include near-infrared indocy- 
Froemel et al.: A Review of Thrombosis and Antithrombotic Therapy in Microvascular
Surgery

anine green video angiography, which provides real-time information on arterial and venous patency [24], and thromboelastography, a test capable of detecting hypercoagulable states that can be used for predicting postoperative thromboembolic complications. These methods are still being tested in the clinical setting. Finally, in a recent report, Parker et al. [25] showed that a functional fibrinogen/platelet ratio above $42 \%$, as measured by $\mathrm{TEG}^{\circledR}$, might be useful for identifying those patients most likely to develop thrombotic complications.

\section{Pharmacological Intervention}

In the absence of large-scale randomized clinical trials in microsurgery patients, guidelines for the use of antithrombotic therapy must be derived from clinical studies performed in patients with coronary disease or stroke. At present, most services performing microsurgery follow their own antithrombotic regime, based on a combination of aspirin, heparin and colloidal fluids, to decrease platelet function, counteract thrombin and increase blood rheology, respectively. Below we provide a brief description of each of these agents and their use in microsurgery.

\section{Heparin}

Heparin is an anticoagulant produced by basophils and mast cells that prevents the formation of new clots and the growth of existing clots in blood vessels. Heparin prevents clot formation by binding to the enzyme inhibitor antithrombin III, which in turn inactivates thrombin and other proteases involved in blood clotting. Clinically, heparin is used in its lowmolecular-weight forms (enoxaparin, dalteparin and tinzaparin) to prevent clot formation in a variety of different disease states (acute coronary syndrome, atrial fibrillation, deep venous thrombosis and pulmonary embolism), clinical interventions (cardiopulmonary bypass surgery, extracorporeal membrane oxygenation for extracorporeal life support, hemofiltration, indwelling central or peripheral venous catheters and vascular surgery) and to coat surfaces of different devices.

Since heparin does not break down preexisting clots, but instead prevents new clots from forming, in microsurgery it is administered preoperatively to prevent clot formation at the site of vessel anastomosis.

In a rat model, Hudson et al. [26] demonstrated the antithrombotic effect of heparin at an anastomosis by inserting a venous catheter proximal to the repaired vessel and found $100 \%$ of free flaps survived compared to $90 \%$ in controls. Local irrigation for 10 min may enhance vessel patency [27] or at least decrease side effects compared to systemic application [28], but high irrigation pressure $(<100 \mathrm{~mm} \mathrm{Hg})$ [29] must be avoided so as not to injure the endothelium.

LMWH has some advantages over unfractionated heparin (UFH), such as bioavailability, lower risk of side effects like heparin-induced thrombocythemia [30] and presumably lower risk of bleeding [31]. These benefits seem to justify disadvantages of LMWH like limited possibilities for drug monitoring by partial thromboplastin time [32]. The steady dose-response relationship of LMWH makes them safe even in high-risk diseases such as kidney deficiency, which has a risk of LMWH accumulation.

Both UFH and LMWH are known to have antithrombin III-independent effects in terms of their release of NO [33] or tissue factor pathway inhibitors [34]. This may also explain why study results differ in the debate of whether LMWH is as effective on arterial thrombosis as UFH.

Summarizing, heparin and LMWH have been shown to reduce the prevalence of venous and arterial thrombosis by approximately $50-60 \%$ when compared to no anticoagulation 
$[35,36]$. Compared to aspirin or dextran, the bleeding risk is highest among heparin [37] and overall LMWH shows fewer side effects than UFH [38].

Aspirin

Acetylsalicylic acid irreversibly blocks cyclooxygenase, which normally produces thromboxane and other procoagulatory factors that activate platelets. The mechanisms by which aspirin exerts this effect are discussed in detail in the accompanying manuscript; therefore, we will focus instead on aspirin administration in microsurgery clinical studies here.

Although aspirin inhibits platelet function more effectively than heparin, and preoperative administration has been shown to prevent both arterial and venous thrombosis, it is less effective than heparin in preventing clot formation at the site of vessel anastomosis [39]. The time of aspirin administration is important. Kort et al. [40] observed that when administered 30 min prior to surgery aspirin had no antithrombotic effect, while other authors describe a significant increase in vessel patency when administered $10 \mathrm{~h}$ preoperatively [41]. Low-dose ( $5 \mathrm{mg} / \mathrm{kg}$ ) aspirin has been shown to be sufficient to irreversibly block platelet thromboxane production while at the same time preserving endothelial prostaglandin $\mathrm{I}_{2}$ and other antithrombotic prostaglandin synthesis [42].

\section{Dextran/Hydroxyphenylacetate}

Dextran is a complex polysaccharide made of many glucose molecules and is composed of chains of varying lengths. It is used as an antithrombotic (antiplatelet) to reduce blood viscosity and as a volume expander in anemia. Dextran 40 is one of several groups of colloidal fluids that are preferred in the US whereas hydroxyphenylacetate $(6 \%)$ is more commonly used in Europe. Both are used for their antiplatelet and antifibrin effect [43], which occur via cell coating or their inhibition of $\alpha_{2}$-antiplasmin effects [44]. When used as plasma expanders, dextran has been shown to provide additional benefits through hemodilution and the associated improvement in blood rheological properties [45]. Risks associated with the use of dextran, such as unwanted bleeding, allergic reactions, acute renal failure [46] and cerebral edema, have been proposed but not proven in well-controlled trials. At the same time, significant improvements in clinical outcomes have not been demonstrated [47]. Disa et al. [48] compared aspirin versus dextran in free flap procedures and found no difference, but did report an increase in side effects in the dextran group. Riva et al. [49] compared prostaglandin $\mathrm{E}_{1}$ and dextran and showed no improvement. Because of these unremarkable results, their potential risks and alternative anticoagulation, dextran has not gained widespread use in microsurgery.

\section{Thrombolytic or Fibrinolytic Drugs}

Like heparin and aspirin, fibrinolytic drugs (streptokinase, alteplase, reteplase and tenecteplase) are used to treat a variety of different disease states (myocardial infarction, thromboembolic strokes, deep venous thrombosis and pulmonary embolism) in which thrombosis is a risk. However, different from heparin and aspirin, these agents are able to dissolve existing clots. These drugs have been found to be most effective when administered within the first $60 \mathrm{~min}$ after a thrombotic event. They are often administered in combination with other anticoagulant drugs, such as intravenous heparin or LMWH, for synergistic antithrombotic effects and secondary prevention.

As it relates to microsurgery, thrombolytic drugs have been shown to be more effective than heparin or dextran in dissolving clots [50] and, in a limited number of clinical trials, have been reported to be able to 'rescue' vessel anastomoses postoperatively [51]. In spite of these reports, others have reported that their use did not significantly increase free flap salvage rates [52]. The reason for this could be that the observed poor flap perfusion might be caused 
Froemel et al.: A Review of Thrombosis and Antithrombotic Therapy in Microvascular Surgery

by factors other than thrombotic occlusion of the pedicle anastomosis, i.e. embolic occlusion of the downstream flap microcirculation (see above). Due to the limited number of wellcontrolled trials, there are no definitive conclusive results regarding efficacy and appropriate dosing [5]. The risk of bleeding can be minimized by drainage [53].

\section{Less Commonly Used Drugs}

Pentoxifylline has been shown to improve microcirculatory perfusion and oxygenation in free flaps due to its effect of improving blood viscosity [54]. It has been described as being most effective when administration is begun 2 weeks prior to surgery. Pentoxifylline has been shown to significantly improve arterial patency, but it should not to be used in combination with LMWH. While the mechanisms differ, when used together they might have an undetermined antagonistic effect, as animal experiments have shown decreased patency [55].

Other clinically available antithrombotic agents are iloprost, a synthetic analogue of prostacyclin (prostaglandin $\mathrm{I}_{2}$ ) [56], hiruidin, which is extracted from the saliva of leeches and can inactivate thrombin antithrombin III $[27,57]$, and ketorolac, a nonsteroidal anti-inflammatory drug in the family of heterocyclic acetic acid derivatives that acts by inhibiting the body's synthesis of prostaglandins [58].

Antithrombotic agents in development include, rivaroxaban [59], glycoprotein II/III antagonists [60], different snake venoms [61], clopidogrel [62] and recombinant tissue factor pathway inhibitors [33].

\section{Current Recommendations for Therapy}

\section{Evidence from Clinical Trials}

Recommendations for the use of anticoagulation therapy in microsurgery vary greatly. In a 6-month prospective clinical study, 23 surgeons operated 493 free flaps and compared dextran, aspirin and heparinized irrigation showing no significant differences [63].

Considering that most patients fit into the category of general recommendations for thrombosis prophylaxis, overall heparin seems to be the first choice. This is the recommendation made by the German Language Working Group for Microsurgery of the Peripheral Nerves and Vessels. LMWH (administered subcutaneously) is considered to be better than UFH; continuous UFH is preferred only in patients with complicating factors like renal insufficiency.

\section{Initiation of Drug Administration}

The time point when an agent is administered is of crucial interest. Khouri et al. [64] found a nonsignificant decrease in flap failure when preoperative aspirin, dextran or heparin was used. Several surgeons recommend the use of heparin administered preoperatively, especially in at-risk patients. No evidence is available indicating that intraoperative bolus administration of heparin is beneficial. When used as the only antithrombotic drug, aspirin must be administered several hours before surgery to be effective. However, since aspirin increases the risk of bleeding, in cases that cause large bleeding donor sites, surgeons in Europe generally avoid using it for prophylaxis. In contrast, in cases of finger replants or flaps in the lower extremities, aspirin is used more frequently [65].

The duration of postoperative anticoagulant treatment described in the literature varies greatly, ranging from 3 days to 2 months. If a patient is maintained on a combination of agents, such as aspirin and dextran or aspirin and heparin, typically one of the agents is used for 3-7 days and then discontinued leaving the patient on a single drug for an extended period. In many cases, both agents are discontinued simultaneously after 3-7 days. 


\section{Combination Therapy and Add-Ons}

The reason for using drug combinations is to reduce the side effects and increase the efficacy. Li and Cooley [3] described arterial and venous patency rates that approached $100 \%$ when heparin, aspirin and dipyridamole were used together. Increased risk of bleeding limits the use of these combined therapies to high-risk groups, however precise specifications regarding their administration do not exist.

\section{Implications for Future Research and Conclusion}

As has been mentioned throughout this review, antithrombotic treatment and prophylaxis regimens in microsurgery vary greatly from surgeon to surgeon and from institution to institution. The reason for this is the lack of large, well-controlled, clinical trials that compare the multiple treatments being used. In the absence of these trials, treatments will continue to be mixed, and best practice recommendations will not be impossible.

Careful preoperative patient selection and risk analysis together with a well-planned surgical strategy continues to be the best approach. This will minimize the risks of intra- or postoperative thrombosis. The investigation, development and introduction of new, safer and more effective antithrombotic agents continue. However, without well-controlled studies that measure and compare their safety and effectiveness to existing treatments, it is possible that 20 years from now someone will write a follow-up review to this one and start by saying 'not much has changed'.

In conclusion, the best antithrombotic prophylaxis and treatment in microsurgery consists of a multistep approach, focusing on risk-adapted monitoring and intervention. Considering the undisputed importance of a good microsurgical technique, quality microsurgical training cannot be underemphasized.

\section{Acknowledgments}

The authors would like to thank Dr. Achim Braunbeck for his assistance with the first draft of this paper.

The work described herein was supported in part by the Friedrichsheim Foundation in Frankfurt, Germany.

\section{References}

1 Johnson PC, Barker JH: Thrombosis and antithrombotic therapy in microvascular surgery. Clin Plast Surg 1992;19:799-807.

2 Veravuthipakorn L, Veravuthipakorn A: Microsurgical free flap and replantation without antithrombotic agents. J Med Assoc Thai 2004;87:665-669.

- 3 Li X, Cooley BC: Effect of anticoagulation and inhibition of platelet aggregation on arterial versus venous microvascular thrombosis. Ann Plast Surg 1995;35:165-169, discussion 169-170.

- 4 Ichinose A, Tahara S, Terashi H, Nomura T, Omori M: Short-term postoperative flow changes after free radial forearm flap transfer: possible cause of vascular occlusion. Ann Plast Surg 2003;50:160-164.

5 Kroll SS, Schusterman MA, Reece GP, Miller MJ, Evans GR, Robb GL, Baldwin BJ: Choice of flap and incidence of free flap success. Plast Reconstr Surg 1996;98:459-463.

6 Suh JD, Sercarz JA, Abemayor E, Calcaterra TC, Rawnsley JD, Alam D, Blackwell KE: Analysis of outcome and complications in 400 cases of microvascular head and neck reconstruction. Arch Otolaryngol Head Neck Surg 2004;130:962-966.

7 Kwaan HC: Microvascular thrombosis: a serious and deadly pathologic process in multiple diseases. Semin Thromb Hemost 2011;37:961-978.

8 Acland R: Thrombus formation in microvascular surgery: an experimental study of the effects of surgical trauma. Surgery 1973;73:766-771. 
Froemel et al.: A Review of Thrombosis and Antithrombotic Therapy in Microvascular Surgery

9 Mayne R: Collagenous proteins of blood vessels. Arteriosclerosis 1986;6:585-593.

10 Bentz ML, Sheppeck RA, Macpherson T, Garrett KO, Billiar T, Dickson CS, Janosky J, Johnson PC: Vasospasm and platelet deposition in human arteries: effects of topical methylene blue. Plast Reconstr Surg 1991;88: 851-859.

11 Fathi M, Fathi H, Mazloumi M, Khalilzadeh O, Amanpour S, Meysamie A, Mashali L, Kardar MH: Preventive effect of botulinum toxin A in microanastomotic thrombosis: a rabbit model. J Plast Reconstr Aesthet Surg 2010;63:e720-e724.

12 Brüner S, Bickert B, Sauerbier M, Germann G: Concept of arteriovenous loupes in high-risk free-tissue transfer: history and clinical experiences. Microsurgery 2004;24:104-113.

13 Jokuszies A, Niederbichler A, Herold C, Dodic T, Vogt PM, AWMF: The current evidence-based guidelines regarding prophylaxis of venous thrombOembolism and their relevance for plastic surgery (in German). Handchir Mikrochir Plast Chir 2010;42:251-259.

14 Kadota H, Sakuraba M, Kimata Y, Yano T, Hayashi R: Analysis of thrombosis on postoperative day 5 or later after microvascular reconstruction for head and neck cancers. Head Neck 2009;31:635-641.

15 Barker JH, Acland RD, Anderson GL, Patel J: Microcirculatory disturbances following the passage of emboli in an experimental free flap model. Plast Reconstr Surg 1992;90:95-102.

16 Barker JH, Acland RD, Gu JM, Wyllie F, Anderson GL: Experimental study of the relationship between alterations in tissue perfusion and anastomotic patency in an experimental free flap. Microsurgery 1993;14:409_ 415.

17 Barker JH, Gu JM, Anderson GLA, O’Shaughnessy M, Johnson P, Galletti G, Acland RD: The effects of heparin and dietary cod liver oil on embolic events in the microcirculation downstream from a small artery repair. Plast Reconstr Surg 1993;91:335-343.

18 O'Shaughnessy M, Anderson GL, Acland RD, Barker JH: Platelet-derived thromboxane $\mathrm{A}_{2}$ decreases microvascular perfusion after arterial repair. Plast Reconstr Surg 1997;99:834-841.

19 Buncke HJ Jr, Schulz WP: Total ear reimplantation in the rabbit utilising microminiature vascular anastomoses. Br J Plast Surg 1966;19:15-22.

20 Kleinert HE, Kasdan ML: Anastamosis of digital vessels. J Ky Med Assoc 1965;63:106-108.

21 Weiland AJ, Moore JR, Daniel RK: The efficacy of free tissue transfer in the treatment of osteomyelitis. J Bone Joint Surg Am 1984;66:181-193.

22 Frankfurt Microsurgery Teaching Course. www.microsurgerycourse.de

23 Vijan SS, Tran VN: Microvascular breast reconstruction pedicle thrombosis: how long can we wait? Microsurgery 2007;27:544-547.

24 Holm C, Dornseifer U, Sturtz G, Basso G, Schuster T, Ninkovic M: The intrinsic transit time of free microvascular flaps: clinical and prognostic implications. Microsurgery 2010;30:91-96.

25 Parker RJ, Eley KA, Von Kier S, Pearson O, Watt-Smith SR: Functional fibrinogen to platelet ratio using thromboelastography as a predictive parameter for thrombotic complications following free tissue transfer surgery: a preliminary study. Microsurgery 2012;32:512-519.

26 Hudson DA, Engelbrecht G, Duminy FJ: Another method to prevent venous thrombosis in microsurgery: an in situ venous catheter. Plast Reconstr Surg 2000;105:999-1003.

27 Fu K, Izquierdo R, Walenga JM, Fareed J: Comparative study on the use of anticoagulants heparin and recombinant hirudin in a rabbit traumatic anastomosis model. Thromb Res 1995;78:421-428.

-28 Khouri RK, Sherman R, Buncke HJ Jr, Feller AM, Hovius S, Benes CO, Ingram DM, Natarajan NN, Sherman JW, Yeramian PD, Cooley BC: A phase II trial of intraluminal irrigation with recombinant human tissue factor pathway inhibitor to prevent thrombosis in free flap surgery. Plast Reconstr Surg 2001;107:408-415, discussion 416-418.

29 Yan JG, Yousif NJ, Dzwierzynski WW, Matloub HS, Sanger JR, Shehadi IE, Siegesmund KA: Irrigation pressure and vessel injury during microsurgery: a qualitative study. J Reconstr Microsurg 2004;20:399-403.

-30 Fabris F, Luzzatto G, Stefani PM, Girolami B, Cella G, Girolami A: Heparin-induced thrombocytopenia. Haematologica 2000;85:72-81.

-31 Malm K, Dahlbäck B, Arnljots B: Prevention of thrombosis following deep arterial injury in rats by bovine activated protein $C$ requiring co-administration of bovine protein S. Thromb Haemost 2003;90:227-234.

32 Dunn CJ, Goa KL: Enoxaparin. A pharmacoeconomic appraisal of its use in thromboembolic prophylaxis after total hip arthroplasty. Pharmacoeconomics 1996;10:179-190.

-33 Tangphao 0, Chalon S, Moreno HJ Jr, Abiose AK, Blaschke TF, Hoffman BB: Heparin-induced vasodilation in human hand veins. Clin Pharmacol Ther 1999;66:232-238.

-34 Nader HB, Walenga JM, Berkowitz SD, Ofosu F, Hoppensteadt DA, Cella G: Preclinical differentiation of low molecular weight heparins. Semin Thromb Hemost 1999;25(suppl 3):63-72.

-35 Zhang B, Dougan P, Wieslander JB: A comparison of the early antithrombotic effects between low molecular weight heparin and heparin in small arteries following a severe trauma: an experimental study. Ann Plast Surg 1993;31:255-261.

-36 Stockmans F, Stassen JM, Vermylen J, Hoylaerts MF, Nyström A: A technique to investigate microvascular mural thrombus formation in arteries and veins: II. Effects of aspirin, heparin, r-hirudin, and G-4120. Ann Plast Surg 1997;38:63-68.

37 Pugh CM, Dennis RH 2nd, Massac EA: Evaluation of intraoperative anticoagulants in microvascular free-flap surgery. J Natl Med Assoc 1996;88:655-657. 
-38 Bijsterveld NR, Hettiarachchi R, Peters R, Prins MH, Levi M, Büller HR: Low-molecular weight heparins in venous and arterial thrombotic disease. Thromb Haemost 1999;82(suppl 1):139-147.

-39 Cooley BC, Gould JS: Experimental models for evaluating antithrombotic therapies in replantation microsurgery. Microsurgery 1987;8:230-233.

-40 Kort WJ, Hulsman LO, van Schalkwijk WP, Weijma IM, Zondervan PE, Westbroek DL: Reductive effect of aspirin treatment on primary tumor growth and metastasis of implanted fibrosarcoma in rats. J Natl Cancer Inst 1986; 76:711-720.

41 Salemark L, Wieslander JB, Dougan P, Arnljots B: Effect of low and ultra low oral doses of acetylsalicylic acid in microvascular surgery. An experimental study in the rabbit. Scand J Plast Reconstr Surg Hand Surg 1991; 25:203-211.

-42 Peter FW, Franken RJ, Wang WZ, Anderson GL, Schuschke DA, O’Shaughnessy MM, Banis JC, Steinau HU, Barker $\mathrm{JH}$ : Effect of low dose aspirin on thrombus formation at arterial and venous microanastomoses and on the tissue microcirculation. Plast Reconstr Surg 1997;99:1112-1121.

-43 Conrad MH, Adams WP Jr: Pharmacologic optimization of microsurgery in the new millennium. Plast Reconstr Surg 2001;108:2088-2096, quiz 2097.

44 Johnson PC: Platelet-mediated thrombosis in microvascular surgery: new knowledge and strategies. Plast Reconstr Surg 1990;86:359-367.

45 Barker JH, Hammersen F, Galla TJ, Bondàr I, Zeller P, Menger MD, Messmer K: Direct monitoring of capillary perfusion following normovolemic hemodilution in an experimental skin-flap model. Plast Reconstr Surg 1990;86:946-954.

-46 Vos SC, Hage JJ, Woerdeman LA, Noordanus RP: Acute renal failure during dextran-40 antithrombotic prophylaxis: report of two microsurgical cases. Ann Plast Surg 2002;48:193-196.

47 Ridha H, Jallali N, Butler PE: The use of dextran post free tissue transfer. J Plast Reconstr Aesthet Surg 2006; 59:951-954.

48 Disa JJ, Polvora VP, Pusic AL, Singh B, Cordeiro PG: Dextran-related complications in head and neck microsurgery: do the benefits outweigh the risks? A prospective randomized analysis. Plast Reconstr Surg 2003; 112:1534-1539.

49 Riva FM, Chen YC, Tan NC, Lin PY, Tsai YT, Chang HW, Kuo YR: The outcome of prostaglandin-E1 and dextran-40 compared to no antithrombotic therapy in head and neck free tissue transfer: analysis of 1,351 cases in a single center. Microsurgery 2012;32:339-343.

50 Rooks MD, Rodriguez J Jr, Blechner M, Zusmanis K, Hutton W: Comparative study of intraarterial and intravenous anticoagulants in microvascular anastomoses. Microsurgery 1994;15:123-129.

51 Goldberg JA, Adkins P, Tsai TM: Microvascular reconstruction of the foot: weight-bearing patterns, gait analysis, and long-term follow-up. Plast Reconstr Surg 1993;92:904-911.

52 Yii NW, Evans GR, Miller MJ, Reece GP, Langstein H, Chang D, Kroll SS, Wang B, Robb GL: Thrombolytic therapy: what is its role in free flap salvage? Ann Plast Surg 2001;46:601-604.

-53 Schubert W, Hunter DW, Guzman-Stein G, Ahrenholz DH, Solem LD, Dressel TD, Cunningham BL: Use of streptokinase for the salvage of a free flap: case report and review of the use of thrombolytic therapy. Microsurgery 1987;8:117-121.

54 Dettelbach HR, Aviado DM: Clinical pharmacology of pentoxifylline with special reference to its hemorrheologic effect for the treatment of intermittent claudication. J Clin Pharmacol 1985;25:8-26.

-55 Murthy P, Riesberg MV, Hart S, Bustillo A, Duque CS, Said S, Civantos FJ: Efficacy of perioperative thromboprophylactic agents in the maintenance of anastomotic patency and survival of rat microvascular free groin flaps. Otolaryngol Head Neck Surg 2003;129:176-182.

-56 Kort WJ, de Kam J, Westbroek DL: Per-operative topical administration of ZK 36374 (iloprost) acts favorably on patency of small artery anastomoses in rats. Microsurgery 1987;8:17-21.

57 Agnelli G, Renga C, Weitz JI, Nenci GG, Hirsh J: Sustained antithrombotic activity of hirudin after its plasma clearance: comparison with heparin. Blood 1992;80:960-965.

-58 Lee KT, Jeon BJ, Lim SY, Pyon JK, Bang SI, Oh KS, Mun GH: The effects of ketorolac on microvascular thrombosis in lower extremity reconstruction. Plast Reconstr Surg 2012;129:1322-1327.

59 Witt DM: ACP Journal Club: rivaroxaban and usual care had similar rates of recurrent VTE and bleeding in symptomatic PE. Ann Intern Med 2012;157:JC2-JC6.

60 Ching S, Thoma A, Monkman S, Kelton JG: Inhibition of microsurgical thrombosis by the platelet glycoprotein IIb/IIIa antagonist SR121566A. Plast Reconstr Surg 2003;112:177-185.

61 Kini RM: Toxins in thrombosis and haemostasis: potential beyond imagination. J Thromb Haemost 2011; 9(suppl 1):195-208.

62 Basile AP, Fiala TG, Yaremchuk MJ, May JW Jr: The antithrombotic effects of ticlopidine and aspirin in a microvascular thrombogenic model. Plast Reconstr Surg 1995;95:1258-1264.

63 Khouri RK, Sherman R, Buncke HJ, Feller AM, Hovius S, Benes CO, et al: A phase II trial of intraluminal irrigation with recombinant human tissue factor pathway inhibitor to prevent thrombosis in free flap surgery. Plast Reconstr Surg 2001;107:408-415.

64 Khouri RK, Cooley BC, Kunselman AR, Landis JR, Yeramian P, Ingram D, Natarajan N, Benes CO, Wallemark C: A prospective study of microvascular free-flap surgery and outcome. Plast Reconstr Surg 1998;102:711-721.

65 Xipoleas G, Levine E, Silver L, Koch RM, Taub PJ: A survey of microvascular protocols for lower-extremity free tissue transfer I: perioperative anticoagulation. Ann Plast Surg 2007;59:311-315. 
66 Askari M, Fisher C, Weniger FG, Bidic S, Lee WP: Anticoagulation therapy in microsurgery: a review. J Hand Surg Am 2006;31:836-846.

67 Schmitz M, Riss R, Kneser U, Jokuszies A, Harder Y, Beier JP, Schäfer DJ, Vogt PM, Fansa H, Andree C, Pierer G, Horch RE: Perioperative coagulation management in microsurgery: report of the consensus workshops in the course of the 31st and 32nd Annual Meeting of the German-language Working Group for microsurgery of the peripheral nerves and vessels (DAM) November 2009 in Erlangen and November 2010 in Basel (in German). Handchir Mikrochir Plast Chir 2011;43:376-383.

68 Brands MT, van den Bosch SC, Dieleman FJ, Bergé SJ, Merkx MA: Prevention of thrombosis after microvascular tissue transfer in the head and neck. A review of the literature and the state of affairs in Dutch Head and Neck Cancer Centers. Int J Oral Maxillofac Surg 2010;39:101-106.

-69 Miller MJ, Schusterman MA, Reece GP, Kroll SS: Interposition vein grafting in head and neck reconstructive microsurgery. J Reconstr Microsurg 1993;9:245-251, discussion 251-252. 